\begin{tabular}{|c|c|c|}
\hline $\begin{array}{l}\text { PKS } \\
\text { PUBLIC } \\
\text { KNOWLEDGE } \\
\text { PROJECT }\end{array}$ & $\begin{array}{c}\text { REVISTA DE GEOGRAFIA } \\
\text { (RECIFE) } \\
\text { http://www.revista.uffe.br/revistageografia }\end{array}$ & $\begin{array}{l}\text { OJS } \\
\frac{\text { OPEN }}{\text { OPENAL }} \\
\text { SYSTEMS }\end{array}$ \\
\hline
\end{tabular}

\title{
AVALIAÇÃO DO POTENCIAL GEOTURÍSTICO DO GEOSSÍTIO GRUTA REFÚGIO DO MAROAGA - PRESIDENTE FIGUEIREDO - AM
}

\author{
Armando Brito da Frota Filho'; Yolanda Tavares Molinaro²; Antonio Jose Teixeira Guerra ${ }^{3}$ \\ ${ }^{1}$ Doutorando pelo Programa de Pós-graduação em Geografia da Universidade Federal do Rio de Janeiro - \\ UFRJ. Email: armandofrota.filho@gmail.com \\ ${ }^{2}$ Bacharel em Geografia pela Universidade Federal do Rio de Janeiro - UFRJ. Email: \\ yolanda_molinaro@hotmail.com \\ ${ }_{3}^{3}$ Professor Titular do departamento de Geografia da Universidade Federal do Rio de Janeiro - UFRJ. Email: \\ antoniotguerra@gmail.com
}

Artigo recebido em 07/12/2017 e aceito em 09/03/2018

\begin{abstract}
RESUMO
O geoturismo surge da preocupação de pesquisadores em valorizar e preservar o patrimônio abiótico, e se pauta nos serviços e facilidades, além da apreciação estética. No presente trabalho, objetivou-se avaliar o potencial geoturístico do geossítio Gruta Refúgio do Maroaga, localizado no município de Presidente Figueiredo, Amazonas. Foram realizados trabalhos de campo, assim como o levantamento de dados secundários da área de estudo. Como resultado, considera-se que o geossítio possui como principais características sua a espeleologia, além de oferecer trilhas guiadas, com paradas interpretativas. O geossítio possui um plano de manejo, relacionado à sua capacidade de carga, considerando a quantidade máxima de pessoas por dia. Apesar de ser notável o potencial geoturístico da área devido a suas características naturais, não existe uma relação entre o geossítio e as comunidades locais, visto que a última não apresenta conhecimento sobre o local, com exceção dos guias das trilhas.
\end{abstract}

Palavras-chave: Geoturismo; Geossítio; Gruta Refúgio do Maroaga

\section{EVALUATION OF THE GEOTURISTIC POTENTIAL OF THE GEOSITE REFUGE OF MAROAGA CAVE- PRESIDENTE FIGUEIREDO - AM}

\begin{abstract}
Geotourism comes up as researchers concern in valorizing and preserving the abiotic heritage, guided by services and conveniences, besides the aesthetic landscape appreciation. This research aimed at evaluating the "Gruta Refúgio do Maroaga's" geotourism potential, located in Presidente Figueiredo Municipality, Amazonas State Field work has been carried out and secondary data have been surveyed, regarding the study area. As results, the geosite has as the main characteristics its speleology, besides offering guided tours, with interpretative stops. The geosite has a management plan, related to its supporting capacity, considering the maximum amount of people it can take per day. Although the remarkable geotourist potential of the area, due its natural characteristics, there is not relation between the geosite and the local communities, considering that the latter do not have any knowledge about the place, except the trails guide.
\end{abstract}

Key-words: Geotourism ; Geosite; Refúgio do Maroaga cave. 


\section{INTRODUÇÃO}

Os conceitos de geodiversidade, geoconservação, geoturismo e patrimônio geológico e geomorfológico têm sido cada vez mais adotados no campo das Geociências, pois atuam como ferramentas a fim de promover a conservação de elementos naturais (abióticos), que mantêm a qualidade de vida das espécies do planeta (BRILHA, 2005; HOSE, 2008); MANTESSO NETO, 2010; CASTRO et al., 2015; JORGE \& GUERRA, 2016). São classificadas como patrimônio geológico as formações geológicas e os afloramentos únicos, assim como outros elementos geológicos que possuem inegável valor científico e ocorrência restrita (MANSUR, 2010; MANSUR et al., 2013).

Nesse contexto, o geoturismo surge da preocupação de pesquisadores em valorizar e preservar o patrimônio abiótico. Segundo Hose (2008), o geoturismo se pauta nos serviços e facilidades interpretativas que permitam aos turistas o conhecimento acerca da geologia e geomorfologia de um local, além da apreciação estética.

Os geoparques possuem inegável ligação com o geoturismo, uma vez que reúnem uma gama de geossítios e representam áreas onde se realiza a geoconservação e o desenvolvimento sustentável, além do estímulo à criação de atividades econômicas pautadas na geodiversidade, envolvendo comunidades locais (BRILHA, 2005). Tendo como base essa discussão, objetivou-se avaliar o potencial geoturístico do Geossítio Gruta Refúgio do Maroaga, localizado no município de Presidente Figueiredo, Amazonas.

A gruta recebe esse nome, devido ao grande chefe e guerreiro indígena Maroaga, que usou a caverna como um esconderijo contra os militares, que queriam construir uma estrada nesta área, durante a década de 1970. Esses índios pertenciam aos Waimiri-Atroari, que praticavam a antropofagia (MUNHOZ, 2010).

\section{MATERIAL E MÉTODOS}

\section{Área de estudo}

O Geossítio Gruta Refúgio do Maroaga, inserido no município de Presidente Figueiredo, a $107 \mathrm{~km}$ da capital do estado do Amazonas, apresenta duas grutas: Gruta do Maroaga e Gruta da Judeia. O geossítio está localizado no interior da APA (Área de Preservação Ambiental) do Maroaga (FIGURA 1) e o acesso à área é realizado a partir do km 8 da estrada da Balbina (rodovia AM-240). 
Figura 1 - Mapa de localização do Geossítio Gruta Refúgio do Maroaga, Presidente Figuereido - AM.

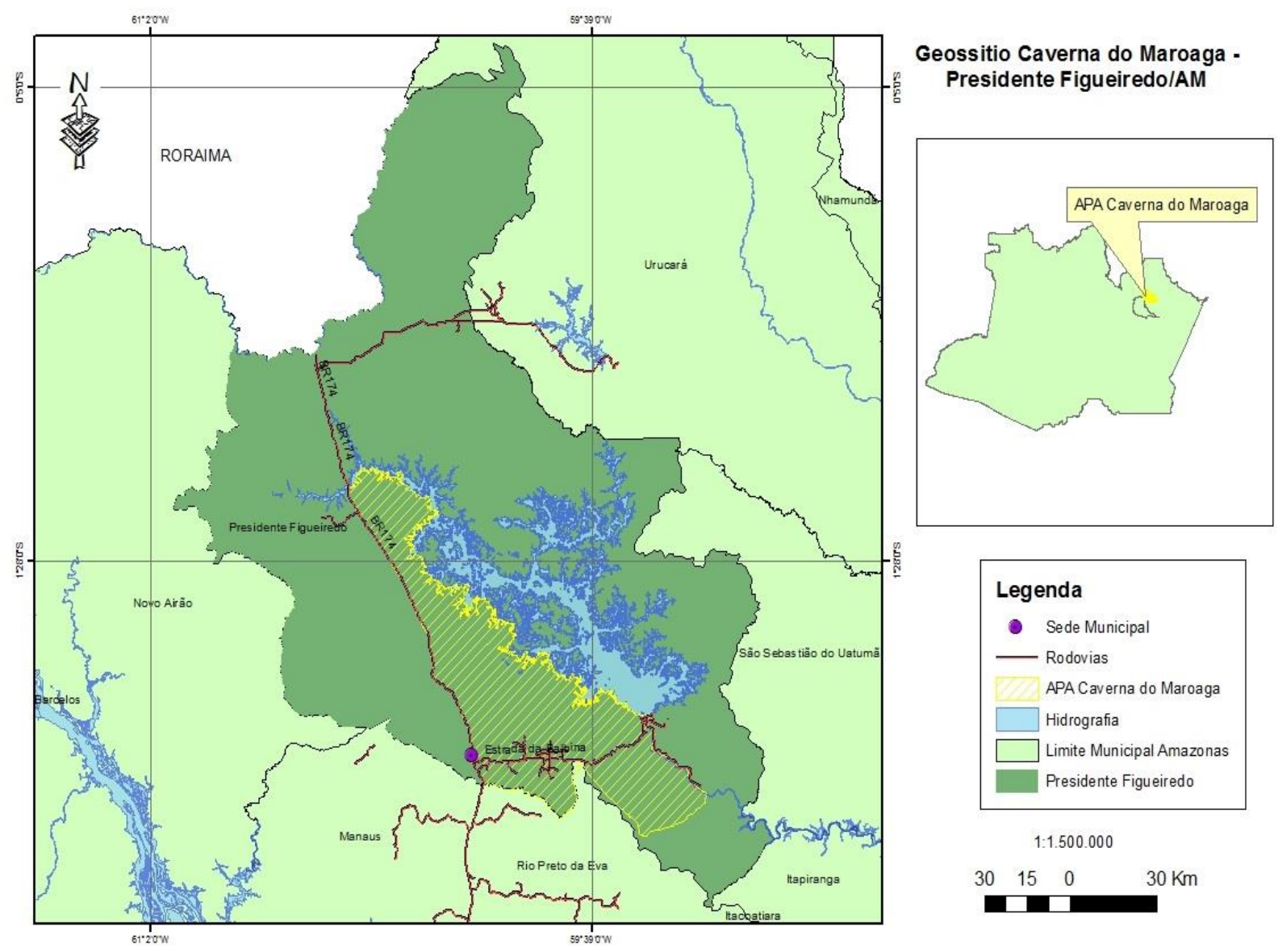

Fonte: Org. Anne Caroline Marinho Dirane, 2017.

Quanto à geologia e geomorfologia do local, Luzardo (2012) descreve que a gruta do Maroaga está em uma encosta de aproximadamente 30m de altura, formada por camadas horizontais de quartzo-arenito, com estratificação plano-paralela pertencentes à Formação Nhamundá, sofrendo processo erosivo causado pela água, dando origem a grutas, lapas e abrigos. A galeria principal da gruta apresenta cerca de $300 \mathrm{~m}$ de comprimento, de onde se ramificam diversas galerias secundárias. $\mathrm{O}$ teto das galerias é em forma de arco e o piso é formado por depósitos de areia acumulados pela água que flui do interior das paredes, remove os grãos da rocha e forma um pequeno rio subterrâneo.

A gruta do Maroaga está inserida em uma área que apresenta clima tropical chuvoso, úmido e quente, cujas chuvas predominam no verão. No que se refere ao microclima no interior da gruta, conforme Nascimento e Molinari (2012), o comportamento da temperatura varia muito pouco, de $22,8^{\circ} \mathrm{C}$ a $25,4^{\circ} \mathrm{C}$, com gradiente de $2,6^{\circ} \mathrm{C}$. 
De acordo com Santos Junior e Limonge (2008), a cobertura vegetal da área de estudo pertence às seguintes formações: Floresta Densa, Floresta Bush e Floresta Secundária, o que demonstra um bom nível de preservação. Em relação à fauna, Trajano e Moreira (1991 apud SANTOS JUNIOR e LIMONGE,2008), registraram cinco espécies de aracnídeos, um camarão, três insetos, dois peixes e um morcego (FIGURA 5).

As cavernas constituem ambientes extremamente peculiares, principalmente pela ausência de luz, nas áreas mais distantes, a partir da entrada. A escuridão completa impede a existência de plantas e, conseqüentemente, a produção primária de nutrientes pelo vegetal. A única fonte de nutrientes é pela bactéria. A maior parte da fonte de energia disponível para os carnívoros é importada de fora da caverna, por morcegos, grandes animais que tingem dentro da caverna, ou entram pelos elos com o exterior, pelos rios, ou pelos caminhos. Portanto, o ambiente da caverna é considerado pobre em nutrientes, quando comparado com o mundo exterior.

\section{Metodologia}

A delimitação do geossítio Gruta do Maroaga foi realizada dentro da proposta “Geoparque Cachoeiras do Amazonas", desenvolvida por LUZARDO (2012), que faz parte de um projeto maior realizado pela CPRM, intitulado "Geoparques do Brasil - Propostas" (SCHOBBENHAUS e SILVA, 2012), com intuito de reunir diversas propostas de Geoparques pelo Brasil.

A fim de alcançar o objetivo proposto, foram realizados trabalhos de campo in loco, que possibilitaram a observação das características das trilhas, tais como: capacidade de carga, qualidade e infraestrutura da trilha e sua segurança, conservação, poluição e destino de resíduos sólidos. Foram realizados levantamentos de dados secundários das características geológico-geomorfológicas, pedo-climáticas e vegetais da área, além das práticas de manejo desenvolvidas e adotadas por entidades privadas e públicas, de esferas municipal e estadual.

\section{RESULTADOS E DISCUSSÕES}

Como dito anteriormente, geossítio está localizado no interior da APA do Maroaga (FIGURA 1), inserida no município de Presidente Figueiredo, fazendo com que o mesmo apresente algumas ações de planejamento voltadas ao turismo natural. De forma explícita e planejada, existe o ecoturismo, e de forma mais sutil, o geoturismo. 


\section{- Potencial geoturístico.}

O geoturismo surge da preocupação de pesquisadores em valorizar e preservar o patrimônio abiótico, tornando-se uma dimensão do turismo, onde as pessoas viajam para apreciar a geodiversidade e o geopatrimônio (NASCIMENTO et al., 2008). O geoturismo é pautado em três princípios fundamentais: base no patrimônio geológico- geomorfológico, pedológico e hidrológico, na sustentabilidade e na informação geológica. Nesse prisma, o geossítio Gruta do Maroaga possui como principais características a sua estratigrafia e espeleologia, visto que a gruta é formada em material cárstico que foi escavado pelo tempo (LUZARDO, 2012).

Com intuito de melhor apresentar as características da área, o geossítio oferece trilhas guiadas, com paradas interpretativas. Tais trilhas mostram a beleza cênica do percurso, visto que o trajeto para a gruta conta com vegetação exuberante e animais nativos.

Ao chegar ao conjunto Gruta do Maroaga (FIGURA 2) e Gruta da Judeia (FIGURA 3), os guias explicam de forma sucinta e didática a formação geológica da área e quais os processos geomorfológicos que tiveram envolvimento no desenvolvimento das grutas, incluindo a ação da água na evolução do relevo cárstico, mencionando ainda quais os animais que vivem dentro das cavernas. A trilha guiada é importante não só pela questão da valorização do patrimônio geológico-geomorfológico, mas também por uma questão de segurança. 
Figura 2 - Interior da Gruta do Maroaga. Notar o teto da gruta em forma de arco, o interior com presença de água.

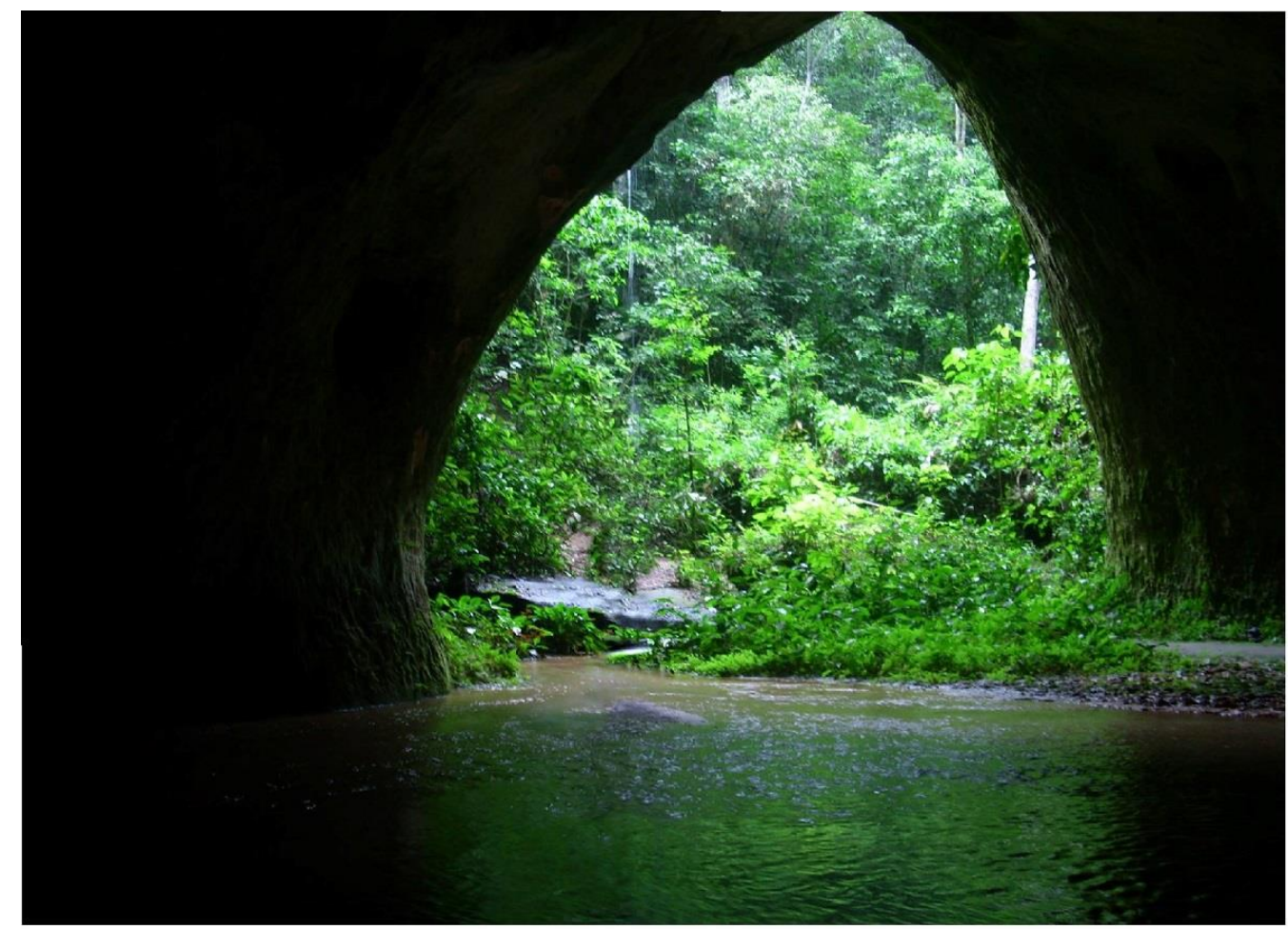

Fonte: André Zumak, 2012.

Figura 3- Exterior da Gruta da Judeia. Notar a presença de água, ao fluxo de água.

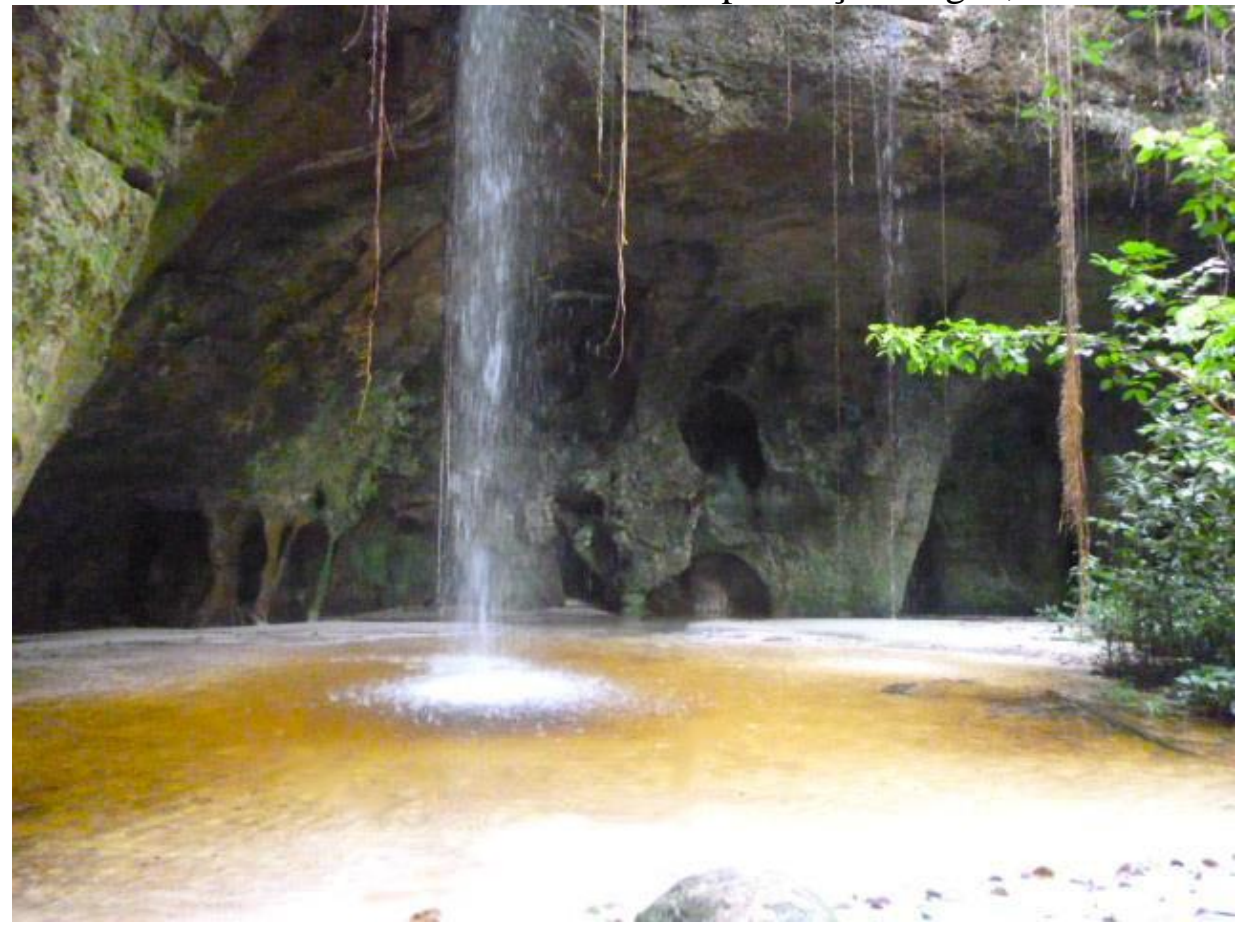

Fonte: André Zumak, 2012 
A gruta do Maroaga não pode ser visitada integralmente, sendo permitida a entrada até cerca de $150 \mathrm{~m}$ adentro da mesma, além de estar vetada a entrada sem os devidos equipamentos para distâncias superiores, pois não apresenta iluminação própria e, devido à presença de morcegos e alta incidência de fungos patogênicos em seu interior, há necessidade de máscaras e tempo limitado de visita (MUNHOZ, 2010; LUZARDO, 2012) (FIGURA 04 e $05)$.

Figura 4 - Interior da Gruta do Maroaga. Presença de fauna nativa no interior da gruta. Interior com presença de água, devido ao canal fluvial que foi responsável por sua escavação.

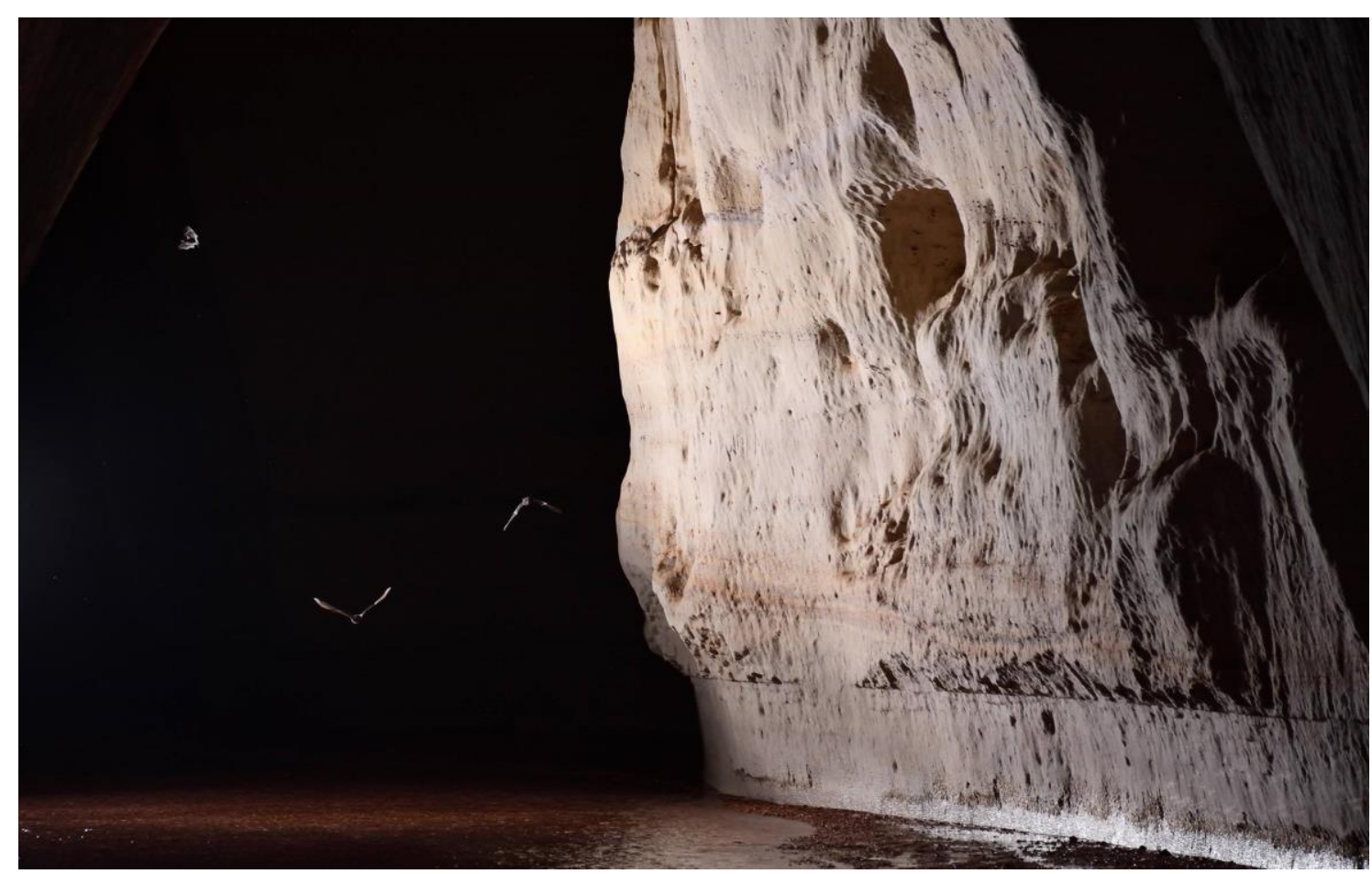

Fonte: André Zumak, 2015 
Figura 05 - Interior da Gruta do Maroaga. Interior com presença de água, devido ao canal fluvial que foi responsável por sua escavação

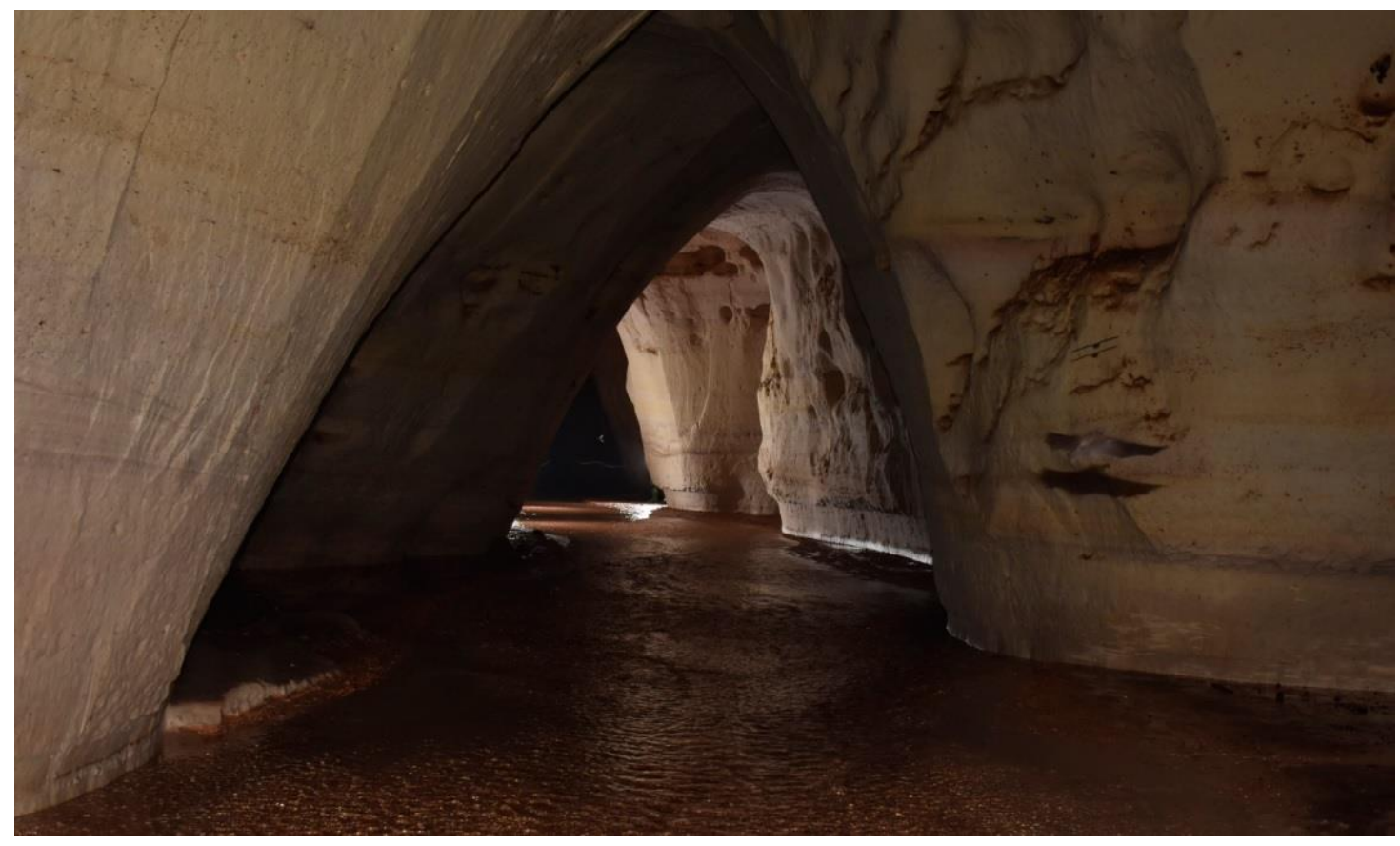

Fonte: André Zumak, 2015.

\section{Infraestrutura das trilhas}

As trilhas do Geossítio Gruta do Maroaga possuem um Plano de Manejo Espeleológico e Projetos Específicos de Infraestrutura, os quais apresentam a capacidade de carga/suporte das trilhas considerando a quantidade máxima de pessoas por dia. Em um percurso de $2 \mathrm{~h}$ a 2:30h, é estimado um número máximo de 15 pessoas, com saídas programadas em intervalo mínimo de uma hora. Como a trilha possui um trajeto circular (com entrada e saída independentes), não havendo necessidade de esperar o retorno do grupo anterior, veta-se a possibilidade de encontro de grupos na caverna (PRESIDENTE FIGUEIREDO, 2004).

Em termos de infraestrutura do trajeto, a trilha apresenta largura média de 2 metros, em terreno irregular, com presença de raízes, porém sem cascalhos no solo para diminuir sua compactação, sendo possível observar pequenas incisões erosivas, como poder observado na figura 6. No que concerne à segurança, a trilha não possui corrimão nas encostas, a fim de facilitar descida e subida, o que pode torná-la de difícil acesso, após eventos chuvosos. 
Figura 06 - Trilha do Maroaga. Notar a irregularidade do terreno

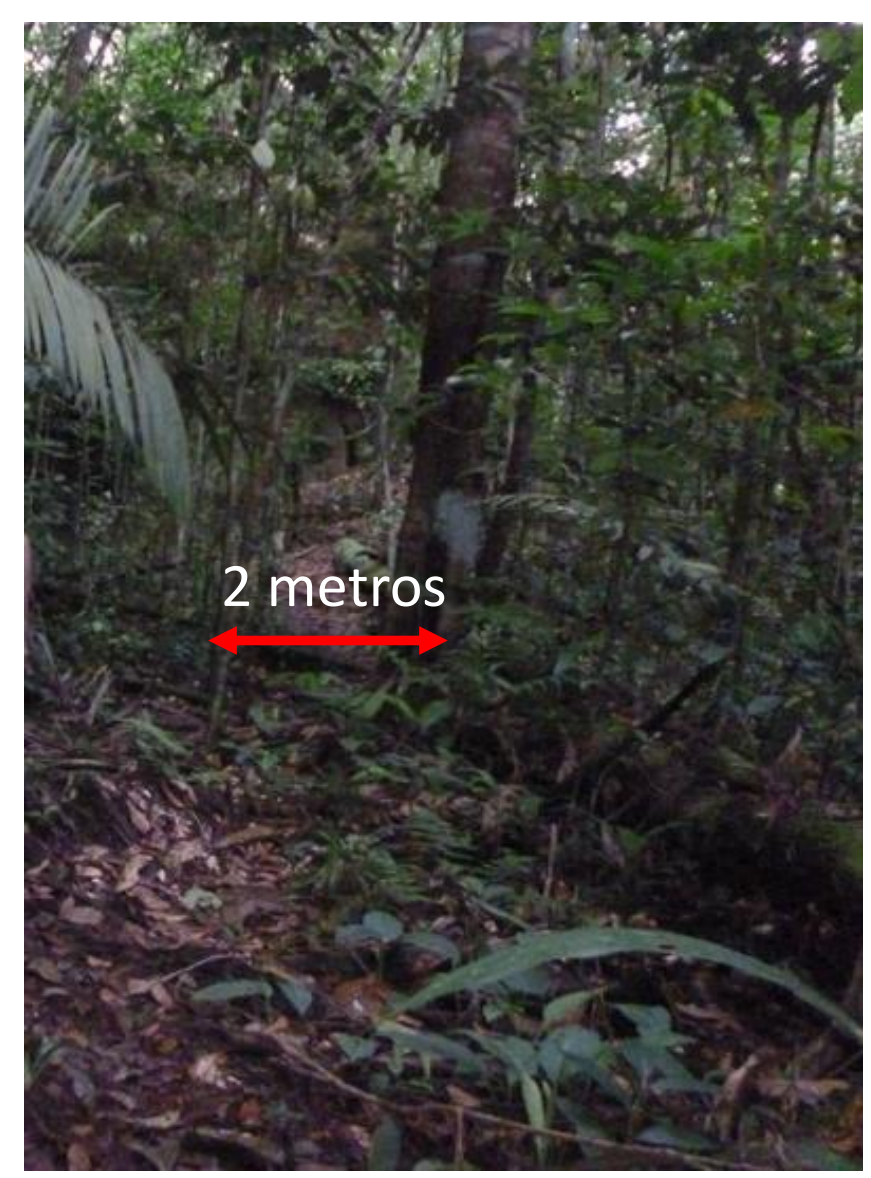

Fonte: Adhonay Dantas, 2017. Org. Armando Brito da Frota Filho, 2017.

Devido às características geomorfológicas e climáticas, a parte da trilha que liga a Caverna do Maroaga à Gruta da Judeia fica parcialmente alagada no período chuvoso (verão), dando origem a uma lâmina d'água que alcança cerca de $30 \mathrm{~cm}$, dificultando a passagem. Quanto às práticas conservacionistas da trilha, é válido ressaltar o trabalho de sensibilização dos guias em relação aos turistas no que se refere ao descarte de resíduos sólidos como latas, garrafas e sacos plásticos, vetando seu porte no decorrer do percurso. Apesar da proibição de porte, ainda é possível encontrar alguns resíduos desta natureza ao longo do trajeto das trilhas. 


\section{Sustentabilidade - a relação da comunidade local com o geossítio}

Como aponta LOPES et al. (2011), o geoturismo deve proporcionar e incentivar atividades econômicas sustentáveis por parte das comunidades locais, tendo como consequência um aumento da oferta de emprego e maior disponibilização de serviços ao turista.

Nesse sentido, trabalhos como o de MUNHOZ (2010) exemplificam que, infelizmente, não existe uma relação entre as comunidades locais e o geossítio Gruta do Maroaga:

"As comunidades rurais do entorno dos atrativos não recebem nenhum tipo de apoio; não há controle do número de turistas em cachoeiras públicas; o que gera um forte impacto ambiental nesses lugares". p87

Além de não haver serviços de orientação ao turista, para além das trilhas, os serviços turísticos prestados são desqualificados, e a atividade turística não está sendo feita de maneira correta, promovendo a degradação ambiental em alguns dos atrativos geológicos, geomorfológicos e ecológicos.

O município de Presidente Figueiredo, por meio da sua Secretaria de Turismo, trata “apenas" do turismo ou ecoturismo, refletindo que a comunidade de forma geral não apresenta conhecimento sobre o geossítio, com exceção dos guias das trilhas. Porém, as visitações à APA Maroaga são permitidas somente quando acompanhadas por guias cadastrados na Prefeitura Municipal de Presidente Figueiredo.

\section{CONSIDERAÇÕES FINAIS}

Com base nos trabalhos de campos realizados e a revisão de literatura da área, é notável o potencial geoturístico do Geossítio do Gruta da Maroaga, uma vez que apresenta características geológico-geomorfológicas singulares, possibilitando algo além da mera apreciação estética da paisagem, permitindo compreender as inter-relações presentes e indissociáveis do meio.

No que tange as comunidades circundantes, o desenvolvimento do geossítio e, a posteriori, do Geoparque, possibilitará o desenvolvimento econômico da região, desencadeado o envolvimento de comunitários, via caráter sustentável e geoconservacionista, assim como a disseminação de conceitos geológico- geomorfológico, que se destacam não só 
no âmbito regional, como nacional e global, visto que, apresenta-se como um geossítio de grandioso potencial geoturístico, por ser o primeiro da região norte e da região amazônica.

\section{AGRADECIMENTOS}

À mestra Anne Caroline Dirane pela elaboração do mapa e ao mestre André Zumak pelas fotos de campo.

\section{REFERÊNCIAS}

BRILHA, J. Patrimônio Geológico e Geoconservação: A Conservação da Natureza na sua Vertente Geológica. Braga: Palimage Editores, 2005.

DOWLING, R. K. Global geotourism — an emerging form of sustainable tourism. Czech Journal of Tourism, v. 2, n. 2, p. 59-79, 2013.

HOSE, T. A. Geotourism and interpretation. In: NEWSOME, D; DOWLING, R. Geotourism: sustainability, impacts and management. Elsevier, p. 221-241.

JORGE, M. C. O. ; GUERRA, A. J. T. . Geodiversidade, Geoturismo e Geoconservação: Conceitos, Teorias e Métodos. Espaço Aberto (UFRJ), v. 6, p. 151-174, 2016.

LOPES, L. S. O.; ARAÚJO, J. L. L.; CASTRO, A. J. F. Geoturismo: Estratégia de geoconservação e de desenvolvimento local/Geotourism: Geoconservation Strategy and Local Development. Caderno de Geografia, v. 21, n. 35, p. 1-11, 2011.

LUZARDO, Renê. "Geoparque Cachoeiras do Amazonas." Schobbenhaus, C. \& Silva, CR Geoparks do Brasil: propostas 1 (2012): 39-58.

MANSUR, K. L. Diretrizes para Geoconservação do Patrimônio Geológico do Estado do Rio de Janeiro. O caso do Domínio Tectônico Cabo Frio. 2010. 214p. Tese de Doutorado. Universidade Federal do Rio de Janeiro, Instituto de Geociências, Rio de Janeiro. 2010.

MANSUR, K. L.; ROCHA, A. J. D.; PEDREIRA, A.; SCHOBBENHAUS, C.; SALAMUNI, E.; ERTHAL, F. C.; PIEKARZ, G.; WINGE, M.; NASCIMENTO, M. A. L.; RIBEIRO, R. R. Iniciativas institucionais de valorização do patrimônio geológico do Brasil. Boletim 
Paranaense de Geociências, v. 70, p. 2-27, 2013.

MUNHOZ, Antonia Neidilê Ribeiro Ecoturismo, Políticas Públicas e Planejamento Participativo e Comunitário no Município de Presidente Figueiredo, no Estado do Amazonas. Manaus: UFAM, 2010. 101 p. Dissertação (Mestrado) — Programa De Pós-Graduação em Ciências do Ambiente e Sustentabilidade na Amazônia - PPG/ CASA, Universidade Federal do Amazonas, Manaus, 2010.

NASCIMENTO, M.; AZEVEDO, Ú. R.; MANTESSO-NETO, V. Geodiversidade, geoconservação e geoturismo: trinômio importante para a conservação do patrimônio geológico. SBGeo, 84p., 2008.

NASCIMENTO, A. Z.; MOLINARI, D. C. Caracterizacao microclimatica preliminarda gruta do Maroaga - municipio Presidente Figueiredo (AM). Revista GeoNorte, v. 2, p. 792-803, 2012.

SANTOS JUNIOR, Aldemir Pereira dos; LIMONGE, Jesseneide Pereira. "Turismo espeleológico na Amazônia: estudo de caso da Caverna do Maroaga em Presidente Figueiredo, ano 2006." Revista Acadêmica Observatório de Inovação do Turismo 2.42008.

SCHOBBENHAUS, Carlos. SILVA, Cassio Roberto da. Geoparques do Brasil: propostas. CPRM, 2012. 